\title{
TOMÁS DE AQUINO E A CRÍTICA À COSMOLOGIA DE VARRÃO: NOTAS SOBRE A RELAÇÃO ENTRE ANIMA MUNDI E IDOLATRIA
}

\section{EVANIEL BRÁS DOS SANTOS ${ }^{1}$}

RESUMO: Este estudo apresenta como Tomás de Aquino, ao ler a cosmologia de Varrão, encontra justificativa cosmológica para o culto da alma do mundo (anima mundi), o que o autor entende como uma prática idolátrica. Para tanto, o texto analisa a articulação tomista entre as noções de divindade, anima mundi e culto. Mais precisamente, é evidenciado que, para Tomás, a forma cósmica não é idêntica com o divino, razão pela qual o culto da anima mundi prestado por Varrão e os romanos se configura como uma falha da razão natural.

PALAVRAS-CHAVE: Anima mundi; idolatria; divindade; Tomás de Aquino; Varrão

ABSTRACT: This study shows how Thomas Aquinas, when reading the cosmology of Varro, finds a cosmological justification for the cult of the soul of the world (anima mundi), which the author understands as a practice of idolatry. For this, the text analyzes the Thomist articulation between the notions of divinity, anima mundi and cult. More precisely, it is evidenced that for Aquinas the cosmic form is not identified with the divine, which is why the worship of the anima mundi by Varro and the Romans is a failure of natural reason.

KEYWORDS: Anima mundi; idolatry; divinity; Thomas Aquinas; Varro

\section{A cosmologia e cosmografia grega e sua influência em Varrão}

A noção de "alma do mundo" (anima mundi), tal como é abordada por Tomás de Aquino (1225-1274) em seus textos, aparece como uma noção transdisciplinar: vinculadas a ela encontram-se ideias metafísicas, cosmológicas e religiosas. ${ }^{2}$ Com efeito, o próprio Tomás é consciente desse estado de coisas, pois, deliberadamente discute a noção de anima mundi em obras filosóficas e teológicas. ${ }^{3}$ Nesse contexto, duas marcas da transdiciplinaridade da noção

\footnotetext{
${ }^{1}$ Doutor em Filosofia pela Universidade Estadual de Campinas (UNICAMP). Pós-doutorando em Filosofia pela Universidade Federal da Bahia (UFBA). Professor da Faculdade Católica de Feira de Santana (FCFS). E-mail: evanielbras@gmail.com.

2 As obras de Tomás serão referenciadas do seguinte modo: ST (Summa Theologiae); SCG (Summa contra gentiles); QDP (Quaestiones Disputatae de Potentia Dei); In Sent. (Scriptum Super Libros Sententiarum Magistri Petri Lombardi); In Physica (In octo libros physicorum Aristotelis expositio); In DCM (In libros Aristotelis De caelo et mundo); In De anima (Sentencia libri De anima); In SBDT (Super Boetium De Trinitate); Cat. aurea in Io, (Catena aurea in Ioannem); Super Io. (Super in Ioannem); QDM (Quaestiones disputatae de malo); In Metaphysica (In duodecum libros Metaphysicorum Aristoteli expositio);

${ }^{3}$ Ver: In De anima I, 5, 8§; In De anima I, 13, 2§; In DCM II, 1, n. 10; QDP, q. 6, a. 6, c; Cat. aurea in Io, c. 1, 1. 3; Super Io., c. 17, 1. 6; SCG I, c. 27; SCG III, c. 120; SCG IV, c. 6; SCG IV, c. 55; In SBDT, q. 1, a. 4, ad8; In
} 
de anima mundi se destacam. Por um lado, na história da filosofia, a noção aparece pela primeira vez com Tales de Mileto, o primeiro filósofo, nomeadamente a partir de sua sentença "omnia esse plena diis" (tudo está pleno de deuses), aliás, supreendentemente, Tomás interpreta tal sentença como uma apologia à adoração da anima mundi, a idolatria (ver: In De anima I, 13, $2 \S)$. Por outro lado, antes mesmo do surgimento da filosofia na Grécia, conforme Tomás, havia uma concepção comum propagada pela mitologia religiosa grega segundo a qual o cosmo (mundo) é um grande animal (ver: In Physica, VIII, 1, n. 2).

A expressão "animal magnum" (grande animal) enquanto predicado do cosmo, ademais, além da semântica religiosa, também possui conotação filosófica, estando os dois domínios presentes em Marco Terêncio Varrão (116 a.C. - 27 a.C.), um dos grandes representantes da filosofia e teologia romana. ${ }^{4}$ Nesse sentido, como pode parecer um tanto óbvio, há em Varrão influência da filosofia e teologia grega, mais precisamente da filosofia e teologia vinculadas à cosmologia, seja a cosmologia filosófica seja a cosmologia religiosa. ${ }^{5}$

Sob a noção de animal magnum enquanto atributo do cosmo, à luz da filosofia e religião grega, encontra-se a noção de "deus” ou “divino", uma tese que aparecerá em Varrão, conforme Tomás, como veremos. Eis a passagem da obra de Tomás na qual o predicado cósmico "animal magnum" é apresentado:

\begin{abstract}
Ainda nesse contexto, ele [Aristóteles] pergunta se o movimento em geral começou em algum instante de modo que antes não houvesse nenhum movimento e, ademais, se o movimento cessará de modo que nenhum ente se mova posteriormente; ou o inverso, isto é, se o movimento nunca começou e nunca cessará, mas sempre existiu e sempre existirá. E estabelece um exemplo que diz respeito aos animais: alguns opinaram que o cosmo é de algum modo um grande animal. Com efeito, estimamos que os animais vivem quando vemos neles algum movimento e, cessando todo movimento, se diz que o animal está morto. Igualmente, em toda a universalidade dos corpos naturais o movimento é considerado como certa vida. Logo, se o movimento sempre existiu, esta certa vida dos corpos naturais será imortal e nunca cessará. (In Physica, VIII, 1, n. 2). ${ }^{6}$
\end{abstract}

SBDT, q. 3, a. 4, c 1; ST, I, q. 3, a. 8, resp.; ST, I, q. 51, a. 1, ad1; ST, I, q. 90, a. 1; a. 4; ST, II-II, q. 94, a. 1, resp.; ST, III, q. 6, a. 3; QDM, q. 16, a. 1, c.

${ }^{4}$ Sabe-se que a filosofia e teologia romana, nomeadamente em Varrão e Cícero, possuem matriz estoica. Existe uma rica literatura sobre o assunto. Dentre outros textos, ver: MOREAU, 1939; DUHOT, 1989; FURLEY, 1989; SEDLEY, 2005; GIL, 2006; MULLER, 2006; MEIJER, 2007; ALGRA, 2009; BELLIOTTI, 2009.

${ }^{5}$ A cosmologia filosófica e a religiosa no âmbito greco-romano são abordadas de modo contundente por Jaeger, ver: JAEGER, 1946. Ver também: JAEGER, 1952; JAEGER, 1961.

6 "Quaerit ergo secundum hoc, utrum motus in communi aliquando esse inceperit, ita quod prius nihil unquam motum fuerit; et quandoque sic deficiat quod nihil postmodum moveatur: aut e contrario, neque unquam inceperit, neque unquam deficiet; sed semper erat, et semper erit. Et ponit exemplum in animalibus, propter hoc quod quidam dixerunt mundum esse quoddam animal magnum. Videmus enim quod animalia vivunt, quamdiu apparet in eis aliquis motus: cessante autem omni motu, dicuntur animalia mori. Sic igitur et in tota universitate naturalium corporum motus consideratur ut vita quaedam. Si ergo motus semper fuit et semper erit, ista quasi vita naturalium corporum erit immortalis et sine cessatione". 
As noções de vida (vita) e movimento (motus), aliás, essenciais para toda a filosofia grega, perdem em importância apenas para a noção de ser (esse), são atribuídas por Tomás na passagem citada a Aristóteles, por um lado e, por outro lado, a "alguns" (quidam), não estando explícito se sob "alguns" encontram-se, além dos poetas (ou mitólogos), os filósofos.

É possível que, dentre os representantes dos filósofos, Tales, Anaximandro, Anaxágoras, Demócrito, Empédocles e Platão estejam subsumidos no pronome "alguns", como veremos. Isso se justifica porque os corpos celestes necessariamente são referenciados neste fragmento presente na passagem supracitada: "em toda a universalidade dos corpos naturais o movimento é considerado como certa vida" (in tota universitate naturalium corporum motus consideratur ut vita quaedam). Ora, conforme Tomás no In Metaphysica, I, 4, os corpos celestes eram cultuados como deuses pela religião natural dos gregos e todos os filósofos mencionados foram religiosamente educados a prestarem culto aos corpos celestes e aos demais deuses gregos. Nesse sentido, a complexa relação entre a filosofia e a religião encontra-se desde o nascimento da filosofia. Com efeito, no In Metaphysica, I, 4, Tomás indica que em Mileto, na Grécia antiga, antes do surgimento da filosofia, os antigos (antiqui) que conduziam a religiosidade grega já haviam estabelecido, numa perspectiva mitológica, uma cosmologia, uma cosmografia e uma teologia que, em alguma medida, influenciaram a filosofia, uma vez que eram consideradas como autoridades (auctoritates). ${ }^{7}$ Nesse sentido, a noção de divindade na Grécia clássica, assim como será para Varrão, é simultaneamente filosófica, ou seja, um princípio apreendido pela razão como causa cósmica, e religiosa, isto é, objeto de culto.

Três são as noções centrais que explicam a cosmologia, a cosmografia e a teologia dos antiqui, conforme Tomás, a saber: água, corpo celeste e divindade. A água é entendida como "o princípio de todas as coisas" (aqua est principium omnium; In Metaphysica, I, 4, n. 15), ou seja, de tudo o que constitui o cosmo. Assim sendo, não somente as coisas particulares são geradas a partir da água, mas também o próprio cosmo foi gerado a partir da água. A água, portanto, para os antiqui, é o princípio universal do cosmo que, por natureza, precede a tudo, inclusive às entidades mais nobres, quais sejam: os corpos celestes e a divindade.

Dentre os deuses imanentes no cosmo, os antiqui prestavam culto aos corpos celestes, sendo as estrelas os corpos divinos mais excelentes porque, por um lado, possuem o movimento

\footnotetext{
7 "Deinde cum dicit sunt autem hic ostendit quomodo Thales inducebatur ad praedictam positionem per auctoritates antiquorum. Et dicit quod aliqui fuerunt antiquiores Thalete et multum ante generationem hominum qui erant tempore Aristotelis, qui fuerunt primo theologizantes, qui visi sunt hanc opinionem de natura habuisse, scilicet quod aqua est principium omnium”. (In Metaphysica, I, 4, n. 15).
} 
mais regular, dando uma volta completa ao redor da Terra em vinte e quatro horas e, por outro lado, seu movimento é o mais veloz no interior do cosmo (ver: In DCM II, 15, n. 2). O movimento estelar, além disso, também contribuiu para o estabelecimento da crença religiosa dos antiqui segundo a qual o cosmo é eterno, uma crença, é importante lembrar, propagada de geração em geração por certos educadores gregos. Aqui, outro texto de Tomás é muito significativo, qual seja: In DCM II, 1, n. 3, 2§.

O ser humano, sobretudo quando criança, é naturalmente inclinado a acreditar nas informações que lhe são transmitidas pelos educadores, principalmente os pais: "É sabido que o costume, especialmente aquele admitido desde criança, adquire a poder de natureza". ${ }^{8}$ Tomás nos informa no In DCM II, 1, n. 3, 2§ que os educadores são os responsáveis imediatos em introduzir os educandos no culto divino, algo que também ocorreu na Grécia antiga. Dentre as crenças transmitidas de geração em geração pelos gregos antigos encontra-se justamente a divinização do corpo celeste, que deveria ser cultuado porque seu movimento não possui término, sendo, por sua vez, influenciador dos acontecimentos naturais e humanos. Ademais, é por causa do movimento perpétuo que os religiosos gregos nomearam o corpo celeste de "deus" (theon), dando início à religiosidade astral, segundo In DCM II, 1, n. 3, $2 \S$.

A religiosidade astral e a filosofia, embora distintas, estão presentes em Tales, conforme o In Metaphysica, I, 4. Com efeito, no texto mencionado, Tomás aborda a teoria de Tales sobre a natureza. Para o autor, a teoria de Tales possui duas fontes distintas, a saber: a observação das entidades naturais que tocam os sentidos e a autoridade dos antigos, isto é, dos educadores de Tales. Na verdade, Tomás acredita que a posição de Tales sobre a natureza é melhor esclarecida mediante a reconstrução do pensamento religiosos antigo sobre a água, o corpo celeste e a divindade. Ao finalizar a reconstrução do pensamento religioso antigo, Tomás registra: “Assim, o que Tales teria pensado sobre a causa primeira das coisas agora está claro" (In Metaphysica, I, 4, n. 17). ${ }^{9}$

Na descrição da teoria da natureza de Tales no In Metaphysica, I, 4, nn. 5-18, Tomás articula as noções de causa material, causa primeira e água. Nesse contexto, é dito que Tales é um dos sete sábios da Grécia, o originador da filosofia especulativa, identificada com a ciência natural, que viveu no período em que Roma foi fundada (ver: In Metaphysica, I, 4, n. 10). Ainda nesse contexto, Tomás afirma, por um lado, que, para Tales, a filosofia primeira é a ciência

\footnotetext{
8 "Consuetudo autem, et praecipue quae est a puero, vim naturae obtinet". (SCG I, 11, 1§).

9 "Sic igitur patet quid Thales de prima causa rerum dicitur existimasse".
} 
natural, uma vez que só é possível conhecer substâncias corpóreas e móveis e, por outro lado, que na cosmografia de Tales a Terra repousa sobre a água (ver: In Metaphysica, I, 4, n. 11).

A filosofia da natureza de Tales está baseada, conforme Tomás, nas noções de causalidade e geração. A causalidade aponta para o princípio do ser, e a geração, por sua vez, para o princípio do devir. A geração pressupõe a causalidade, razão pela qual a causa que é princípio de ser necessariamente será princípio de geração, uma vez que gerar é trazer algo ao ser (ver: In Metaphysica, I, 4, n. 13). “Água”, segundo Tomás, é o nome que Tales confere para o princípio do ser e para o princípio da geração. Além da noção mitológica de oceano enquanto a máxima agregação das águas (ver: In Metaphysica, I, 4, n. 16), a compreensão da água como princípio provém da observação da umidade presente nos seres vivos e, mesmo nos não vivos, como no caso do fogo (ver: In Metaphysica, I, 4, n. 13). Assim sendo, a umidade precede, por natureza, a todas as entidades cósmicas. Se a água é o princípio da umidade, então a água precede a umidade, logo, a água precede, por natureza, a tudo o que existe.

Embora mencione a educação religiosa de Tales, assim como indícios de que ele possui uma teologia natural, Tomás não articula no In Metaphysica, I, 4, nn. 5-18 as noções de "água" e "divindade" para Tales. Com efeito, Tomás articula tais noções no domínio da mitologia dos antiqui no In Metaphysica, I, 4, n. 16, texto no qual é dito que a água e a divindade (Tethys) são consideradas pelos antiqui como os pais da geração das coisas. Nesse sentido, é somente pela referência à educação religiosa de Tales que se pode ter uma breve ideia da possível articulação filosófica entre as noções de água e divindade, para o filósofo de Mileto. Dito de outro modo, conforme Tomás, é somente referenciando a educação religiosa de Tales que podemos entender a relação entre a filosofia e o culto religioso, como no caso da prestação de homenagem a anima mundi empreendida por Tales, assim como posteriormente por Varrão.

É interessante constatar que Tomás, embora caracterize certo seguimento da religião popular grega como de adoradores da anima mundi, assim como Tales, quando discute a noção de anima mundi em Platão e Aristóteles não caracteriza os dois grandes filósofos gregos como “idólatras”. Ao que parece a razão central de Tomás não proceder daquele modo diz respeito ao fato de Platão e Aristóteles não identificarem a anima mundi com uma suprema divinitas.

A expressão "anima mundi" é atribuída a Platão explicitamente por Tomás (ver: Cat. aurea., c. 1, 1. 3; In DCM II, 1, n. 10). O mesmo não ocorre quanto a Aristóteles, muito embora seja possível que a noção esteja presente na cosmologia do Estagirita. O sentido da expressão, para os dois filósofos gregos, conforme os textos de Tomás, possui uma base semântica comum, estando vinculada a três termos, a saber: geocentrismo, finitude e forma e, ademais, vincula-se 
a imago mundi (ou cosmografia) comum a um grupo de filósofos gregos, quais sejam: Anaximandro, Anaxágoras, Demócrito e Empédocles (ver: In DCM II, 20, n. 3).

Todos os filósofos mencionados, além de Platão e Aristóteles, segundo Tomás, possuem uma imago mundi que pode ser descrita do seguinte modo: até a esfera da Lua existem quatro esferas respectivamente, da terra, da água, do ar e do fogo. Ademais, a despeito das possíveis incongruências quanto ao número de esferas celestes, admite-se ao menos uma esfera magna para cada um dos sete planetas, Lua, Sol, Mercúrio, Vênus, Marte, Júpiter e Saturno, assim como uma esfera magna para as estrelas fixas, acima de Saturno, a oitava esfera, que é o limite natural do cosmo. Nesse sentido, a esfera menos extensa é constituída pelo elemento terra e a esfera mais extensa é a oitava. O cosmo, por conseguinte, em seu estado primeiro, é imaginado como uma relação de esferas na qual a esfera superior contém na concavidade de sua superfície a convexidade da superfície da esfera inferior. No centro deste cosmo, além disso, encontra-se a Terra:

\begin{abstract}
A respeito da posição da Terra diz, portanto, que nem todos os filósofos têm a mesma opinião. Com efeito, aqueles que afirmaram que o universo inteiro era infinito não puderam assinalar um determinado sítio para a Terra, pois no infinito não há razão para considerar o meio e os extremos. Porém, muitos filósofos que disseram que o mundo inteiro era finito afirmaram que a Terra está posicionada no meio do mundo, como Anaximandro, Anaxágoras, Demócrito, Empédocles e Platão. (In DCM II, 20, n. 3$)^{10}$
\end{abstract}

A posição da Terra no centro do cosmo só é razoável se o cosmo for finito. A tese geocêntrica, portanto, requer a afirmação cosmológica sobre a finitude cósmica. A finitude cósmica, por sua vez, está associada, como imagem e como ideia, à admissão dos pontos limites do cosmo, na perspectiva do observador, quais sejam: as estrelas e a Terra, os itens que nos auxiliam a entender o que é o cosmo, para alguns filósofos gregos, de Anaximandro até Aristóteles.

Associada à tese da finitude cósmica encontra-se outra, isto é, a tese da unidade cósmica, uma tese que, segundo Tomás, foi sustentada por Platão e Aristóteles (ver: ST, I, q. 47, a. 4, resp.). Com efeito, para os dois pensadores gregos, conforme Tomás, o cosmo é o todo enquanto ordenamento das partes heterogêneas. Este ordenamento, ademais, necessariamente é efeito de uma causa, só havendo duas hipóteses de nomeação da "causa", quais sejam: i. sabedoria ordenadora (sapientia ordinantoris); ii. acaso (casus).

\footnotetext{
10 "Dicit ergo primo quod de situ terrae non omnes philosophi habent eandem opinionem. Quicumque enim posuerunt totum universum esse infinitum, non potuerunt assignare terrae determinatum situm, eo quod in infinito non est accipere medium et extrema. Sed plures eorum qui posuerunt totum mundum esse finitum, dixerunt terram esse positam in medio mundi, sicut Anaximander, Anaxagoras, Democritus, Empedocles et Plato”.
} 
Platão e Aristóteles, para Tomás, escolheram a primeira opção, ou seja, admitiram a sabedoria ordenadora como causa, sendo o cosmo, por sua vez, o efeito:

\begin{abstract}
A razão de ser o cosmo um só é que todas as coisas devem ser ordenadas por uma só ordem e em relação a um. E por isso Aristóteles concluiu a unidade de Deus governador, da unidade da ordem existente nas coisas; e Platão pela unidade do exemplar prova a unidade do cosmo, que é como o exemplado. (ST I, q. 47, a. 4, ad1). ${ }^{11}$
\end{abstract}

Se Platão e Aristóteles admitem a unidade cósmica, conforme a passagem acima, mesmo que por vias distintas, tendo consequências marcadamente distintas, ambos devem admitir também que o cosmo possui uma forma que lhe assegura a unidade, uma vez que é o todo constituído de partes heterogêneas (ver: SCG II, 58, 5§), como o próprio Tomás nos lembra: "o cosmo tem uma forma na matéria" (mundus habet formam in materia; ST, I, q. 47, a. 4, obj. 3). A forma cósmica, ademais, é o princípio interno que ordena a matéria total presente no cosmo, ${ }^{12}$ razão pela qual o todo não é um caos, mas uma entidade harmoniosa e bela, semelhante a um ente vivo que, ao ter conservadas as partes heterogêneas funcionando perfeitamente, é mantido na existência. A noção de forma cósmica, pelo que se percebe, também denota o princípio interno que viabiliza que o "todo" seja nomeado como "cosmo". É, portanto, uma noção necessária à cosmologia filosófica, ${ }^{13}$ sobretudo, aos filósofos que admitem o geocentrismo, a finitude e a unidade cósmica, como nos casos de Anaximandro, Anaxágoras, Demócrito, Empédocles, Platão e Aristóteles. Resta-nos averiguar se, para Platão e Aristóteles, conforme Tomás, a noção de forma cósmica inclui a noção de vita ou anima, o que equivale a afirmar a noção de anima mundi.

Se a hipótese da inclusão é razoável, então é preciso também questionar sobre a natureza e a função da vita ou anima no cosmo, para Platão e Aristóteles, segundo Tomás. Dito de outro modo, é preciso questionar se a anima mundi é material ou imaterial, imanente ou separada e qual o tipo de causalidade que ela exerce sobre o cosmo, ou seja, se ela é causa final e, especialmente, se ela é causa eficiente. Na hipótese de ser causa eficiente, ademais, a investigação deve se concentrar nas noções de primeiro motor (primum movens) e automovente (movere seipsa), pois tais noções são associadas por Tomás com a concepção platônicoaristotélica sobre a causalidade cósmica.

\footnotetext{
11 “AD PRIMUM ERGO DICENDUM quod haec ratio est quare mundus est unus, quia debent omnia esse ordinata uno ordine, et ad unum. Propter quod Aristoteles, in XII Metaphys., ex unitate ordinis in rebus existentis concludit unitatem Dei gubernantis. Et Plato ex unitate exemplaris probat unitatem mundi, quasi exemplati".

12 "mundus constat ex sua tota materia". (ST, I, q. 47, a. 4, ad3).

${ }^{13}$ Assim como é necessária à cosmologia religiosa. Ver: In Physica VIII, 1, n. 2; In DCM II, 1, n. 8.
} 
É importante observar que Tomás trata no mesmo contexto das concepções platônica e aristotélica sobre as noções de primum movens e movere seipsa, o que é feito respectivamente na SCG I, 13, 10§ e no In Physica VII, 1, n. 7. Nestes dois textos, o autor entende que, tanto para Platão como para Aristóteles, o termo "movimento" pode possuir dois sentidos, um mais geral e outro mais específico. No primeiro caso, "movimento" significa "operação", tal como “compreender", "opinar" e "sentir". Quanto ao segundo caso, por sua vez, significa "mudança" nas categorias da quantidade, qualidade e, sobretudo, do lugar.

À luz do segundo sentido, mais precisamente quanto à locomoção, podemos comparar os finais de ambos os textos. O final da SCG I, 13, 10§, escrito antes do verão de 1259 (ver: TORRELL, 1999, p. 332), diz: "Não há diferença entre alcançar um primeiro automovente, como compreende Platão, ou alcançar um primeiro que seja absolutamente imóvel, como compreende Aristóteles" (SCG I, 13, 10§). ${ }^{14}$ Nove ou dez anos depois, ou seja, entre 1268-1269 (ver: TORRELL, 1999, p. 342), Tomás faz afirmações similares no final do In Physica VII, 1, n. 7:

Assim é claro que Aristóteles, ao afirmar que tudo o que se move é movido por outro, não difere de Platão no sentido, o qual sustentou que algumas coisas movem a si mesmas, mas somente nas palavras. ${ }^{15}$

O "primeiro" (primus) alcançado (devenire) no final dos raciocínios filosóficos de Platão e Aristóteles, segundo SCG I, 13, 10§, é uma entidade cosmológica? De modo semelhante podemos questionar, conforme In Physica VII, 1, n. 7: o "outro" (ab alio) aristotélico, assim como o que move a si mesmo (movere seipsa) platônico, é uma entidade cosmológica? Se sim, ambos podem ser compreendidos como a forma cósmica? Embora as questões sejam complexas o suficiente para resguardar prudência, é razoável uma resposta positiva. Se assim for, a forma cósmica platônico-aristotélica é a anima mundi. Portanto, que o cosmo seja um animal magnum não é somente um dado mitológico: está no cerne da cosmovisão de vários filósofos, como Tales, Anaximandro, Anaxágoras, Demócrito, Empédocles, Platão e Aristóteles. Há, por conseguinte, aspectos cosmológicos e cosmográficos comuns a todos estes filósofos gregos, razão pela qual pode-se afirmar a existência de uma imago mundi grega influente nos trabalhos filosóficos posteriores, como é o caso de Varrão.

\footnotetext{
14 “[...] nihil enim differt devenire ad aliquod primum quod moveat se, secundum Platonem; et devenire ad primum quod omnino sit immobile, secundum Aristotelem".

15 "Et sic patet quod Aristoteles, ponens omne quod movetur ab alio moveri, a Platone, qui posuit aliqua movere seipsa, non dissentit in sententia, sed solum in verbis".
} 


\section{Anima mundi e idolatria na cosmologia de Varrão}

A leitura que Tomás empreende a respeito do pensamento e da cosmologia de Varão é estritamente dependente de Agostinho enquanto fonte, nomeadamente do texto De Civitate Dei (Livros VI-VII). Ao longo do De Civitate Dei, Livros VI-VII, Agostinho critica o pensamento e a cosmologia de Varrão, sobretudo porque este, conforme o bispo de Hipona, não postula qualquer resquício de incorporeidade no tocante à natureza do cosmo, sua origem, bem como à operação imanente no cosmo. Nesse sentido, a cosmologia de Varrão é "fisiológica" (physiologica, ver: De Civitate Dei, VII, 5), ou seja, é uma mecânica que investiga as causas eficientes corpóreas, dentre as quais encontra-se "deus" entendido como a causa interna e imanente da locomoção cósmica. ${ }^{16}$

Conforme Agostinho, o cosmo de Varrão é um todo constituído de duas partes maiores, o céu e a terra, estes, por sua vez, divididos em partes menores. O cosmo em sua totalidade, assim como cada uma de suas partes, é analogamente entendido mediante a relação entre a alma e o corpo. Para Varrão, segundo o bispo de Hipona, a alma é o constituinte universal, corpóreo, sutil e imperceptível, ${ }^{17}$ ou seja: “[...] certa força invisível e superiormente poderosa" (vi quadam invisibili ac praepotenti; De Civitate Dei, VII, 17). A força (vis) invisível e maximamente potente é, portanto, a alma cósmica, isto é, a forma da totalidade do cosmo: "Nas suas reflexões preliminares sobre a teologia natural, o citado Varrão emite a sua opinião de que deus é a alma do cosmo (que os gregos designam de кó $\sigma \mu \circ)$ e de que este mesmo cosmo é deus" (De Civitate Dei, VII, 6). ${ }^{18}$

É interessante perceber que, embora leia Varrão a partir do De Civitate Dei, Tomás introduz noções e ideias em sua leitura da cosmologia de Varrão que estão ausentes da leitura de Agostinho. Com efeito, contrariamente a Agostinho, para o doutor angélico há incorporeidade na cosmologia de Varrão, nomeadamente no tocante a "deus" entendido por Varrão como a anima mundi. Ademais, é nesse ínterim que aparece uma discussão bastante

\footnotetext{
16 Ver: BOURKE, 1954.

${ }^{17}$ Ver: De Civitate Dei, VII, 6: "Hic videtur quoquo modo unum confiteri Deum; sed ut plures etiam introducat, adiungit mundum dividi in duas partes, caelum et terram; et caelum bifariam, in aethera et aera; terram vero in aquam et humum; e quibus summum esse aethera, secundum aera, tertiam aquam, infimam terram; quas omnes partes quattuor animarum esse plenas, in aethere et aere immortalium, in aqua et terra mortalium. Ab summo autem circuitu caeli ad circulum lunae aetherias animas esse astra ac stellas, eos caelestes deos non modo intellegi esse, sed etiam videri; inter lunae vero gyrum et nimborum ac ventorum cacumina aerias esse animas, sed eas animo, non oculis videri et vocari heroas et lares et genios".

18 "Dicit ergo idem Varro adhuc de naturali theologia praeloquens deum se arbitrari esse animam mundi, quem

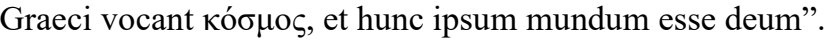


fecunda para o propósito deste estudo, isto é, o tópico sobre a história da religião natural romana entendida à luz do próprio Varrão, um filósofo romano.

Ao citar um trecho da obra perdida de Varrão, a saber: Antiquitates rerum humanarum et divinarum, ${ }^{19}$ Agostinho registra as inquietações do filósofo romano:

\begin{abstract}
A segunda classe de teologia, para que chamei a atenção, é aquela sobre a qual os filósofos nos deixaram muitos livros em que se questiona: os deuses — que são eles? onde residem? qual a sua origem? quais as suas qualidades? Existem desde determinada época, ou são eternos? provêm do fogo, como crê Heráclito? provêm dos números, como afirma Pitágoras, ou dos átomos como pretende Epicuro? e outras questões que se podem ouvir mais facilmente dentro das paredes de uma escola do que cá fora, no fórum. (De Civitate Dei, VI, 5). ${ }^{20}$
\end{abstract}

Os filósofos, segundo Varrão, se questionam a respeito da natureza do divino (ou dos deuses), razão pela qual eles estabelecem a teologia cosmológica. À luz da teologia cosmológica, a natureza divina ou deus é o princípio formal constituinte e inseparável do cosmo. Os filósofos, portanto, conforme Varrão, devem admitir que deus é o gênero divindade, isto é, a natureza divina compartilhada por todos os deuses, como a humanidade que é compartilhada por todos os humanos. Uma consequência direta da admissão da generalidade de deus diz respeito ao atributo da impessoalidade (impersonalis) ao gênero "deus" que é, nesse caso, conforme já afirmado, a divindade compartilhada por todos os deuses, as entidades divinas. A divindade, assim sendo, porque é impessoal, pode razoavelmente ser identificada com a anima mundi.

A anima mundi ou deus, para Varrão, conforme Tomás, é objeto de culto, este que, segundo o doutor angélico, é um falso culto, ou seja, a idolatria. Nesse sentido, a idolatria praticada por Varrão consiste no conhecimento e no assentimento no sentido de "culto interior da mente" (ST, II-II, q. 94, a. 2, obj. 3 ) 21 ou "adoração" da força universal que locomove naturalmente o cosmo, ou seja, da nomeação interior e reverencial do termo "deus" enquanto força cósmica impessoal. Varrão ou qualquer um que pense de modo similar, por conseguinte, teria prestado um culto divino à força cósmica, universal e impessoal.

O culto à força cósmica, ademais, não está restrito aos filósofos, mas também é praticado pelo povo romano, uma prática, aliás, que possui uma história, qual seja, inicia sem as imagens

\footnotetext{
${ }^{19}$ Sobre o texto de Varrão, ver: PEPIN, 1956.

${ }^{20}$ (Trad. João Dias Pereira, 1996-2000, modificada): "Secundum genus est, inquit, quod demonstravi, de quo multos libros philosophi reliquerunt; in quibus est, dii qui sint, ubi, quod genus, quale est: a quodam tempore an a sempiterno fuerint dii; ex igni sint, ut credit Heraclitus, an ex numeris, ut Pythagoras, an ex atomis, ut ait Epicurus. Sic alia, quae facilius intra parietes in schola quam extra in foro ferre possunt aures".

21 “[...] summus Deus interiori cultu mentis est colendus $[\ldots]$ ”.
} 
(ídolos) e, posteriormente, estabelece as imagens: "De dois modos alguns observavam o culto dos deuses estranhos. Assim, uns prestavam culto divino a certas criaturas, sem recorrerem a imagens. Donde o dizer Varrão, que os antigos Romanos cultuaram muito tempo os deuses, sem imagens". (ST, IIa-IIae, q. 122, a. 2, ad 2). ${ }^{22}$

É importante observar que o culto filosófico da anima mundi é direcionado ao incorpóreo, por um lado e, por outro lado, o culto popular dos deuses é direcionado ao invisível. Tomás aponta para a diferença entre incorpóreo e invisível na discussão com Varrão, uma vez que ele menciona a tese de Varrão segundo a qual a instituição de artefatos (ídolos) no culto romano só ocorreu tempos depois de já consolidada a prática interior da adoração dos deuses por parte dos antigos romanos que viveram bem antes de Varrão. Portanto, invisível e incorpóreo não são sinônimos: afirmar sinonímia entre os termos implica em admitir que os antigos romanos referidos por Varrão possuíam um conhecimento filosófico dos deuses, o que não é o caso, pois tratava-se na época dos antigos romanos de prática religiosa no domínio da teologia civil e mitológica, não da teologia cosmológica, que é própria dos filósofos. Nessa medida, para os antigos romanos, os deuses são invisíveis, pois o culto ocorre sem artefatos, mas não são incorpóreos, uma vez que os deuses não são entendidos como entidades que ultrapassam o cosmo, tal como Tomás entende esse termo. ${ }^{23}$ Assim sendo, na época dos antigos romanos, o culto aos deuses, ainda sem os artefatos, não era um culto do incorpóreo, mas tão somente do invisível.

O culto ao incorpóreo na religiosidade romana, conforme Tomás, já aparece em Varrão, como o autor apresenta na ST, Ia, q. 90, a. 1. Com efeito, no texto mencionado, Tomás apresenta uma história da consideração sobre a natureza das coisas (naturas rerum), dividindo-a em três partes, a saber: alguns pré-socráticos, os maniqueus e Varrão. Os pré-socráticos referidos são descritos como pensadores cuja investigação está restrita à corporeidade, noção sob a qual deus, natureza e alma estão compreendidos. Os maniqueus, por seu turno, não apresentam nenhuma diferença relevante, pois entendem que a divindade e a alma são luzes corpóreas. Enfim, ao tratar de Varrão, Tomás escreve:

Ulteriormente, porém, outros conceberam a existência de um ente incorpóreo, não todavia separado do corpo, mas forma deste. Donde dizer Varrão que Deus é uma

\footnotetext{
22 "AD SECUNDUM DICENDUM quod cultus alienorum deorum dupliciter apud aliquos observabatur. Quidam enim quasdam creaturas pro diis colebant absque institutione imaginum: unde Varro dixit quod antiqui Romani diu sine simulacris deos coluerunt".

${ }^{23}$ Cf. In Sent., III, d. 3, q. 2, a. 2; In Sent., III, d. 24, q.1, a. 2; ST, Ia-IIae, q. 110, a.1; SCG III, 54, SCG III, 147.
} 
alma que governa o cosmo pelo movimento e pela razão, como Agostinho relata no De Civitate Dei, VII. (ST, Ia, q. 90, a. 1, resp.). ${ }^{24}$

A noção de deus na teologia cosmológica de Varrão é entendida como a força incorpórea difundida no cosmo. Tal força, além disso, locomove naturalmente o cosmo e mantém todas as partes cósmicas em harmonia, ou seja, é a razão que governa o cosmo. Além disso, a concepção de deus presente em Varrão, conforme Tomás, evidencia um progresso do conhecimento humano sobre a natureza das coisas (natura rerum), se comparada a alguns pré-socráticos e aos maniqueus. Todavia, na concepção de Varrão deus não é compreendido como separado do cosmo enquanto o corpo do todo, uma vez que deus, a anima mundi, é a forma cósmica, isto é, deus é forma corpórea. Nesse sentido, para Varrão, segundo Tomás, não há distinção ontológica entre deus e o cosmo, a forma e o corpo, mesmo porque deus e o cosmo são complementares, na medida em que a existência de um implica a existência do outro. Essa é a razão pela qual a teologia cosmológica de Varrão é uma “fisiologia” (ou mecânica) sobre deus e o cosmo, como já afirmado anteriormente, aliás, essa fisiologia entende o cosmo como um animal magnum, uma influência explícita da imago mundi grega.

O vínculo entre a noção de deus enquanto forma cósmica, anima mundi, e a idolatria é estabelecido pelo próprio Tomás:

Outros, porém, pensavam que todo o cosmo é Deus, não devido à substância corpórea, mas por causa da alma, que consideravam ser Deus. Assim, diziam que Deus não é outro que a alma, governadora do cosmo pelo movimento e pela razão; assim como dizemos que o homem é racional pela alma e não pelo corpo. Por isso ensinavam que se devia prestar culto divino a todo o cosmo e às suas partes - ao céu, ao ar, à água e assim por diante. E a elas referiam os nomes e as imagens dos seus deuses, como afirma Varrão e Agostinho relata no De Civitate Dei, VII. (ST, IIa-IIae, q. 94, a. 1, resp.) ${ }^{25}$

O cosmo, para Varrão, segundo Tomás, é a substância corpórea que é enformada por deus, a forma incorpórea. Como em determinados contextos a forma só possui existência na medida em que enforma certa matéria, como no caso da forma de uma planta ou de um animal, a existência de deus em Varrão é condicionada a enformar o cosmo. Ao enformar o cosmo, não só deus, mas o próprio cosmo em sua totalidade e em suas partes, é objeto de culto divino, seja

\footnotetext{
24 (Trad. Alexandre Corrêa, 1980, modificada): "Secundo vero processum fuit ad hoc, quod aliqui aliquid incorporeum esse apprehenderunt, non tamen a corpore separatum, sed corporis formam. Unde et Varro dixit quod Deus est anima mundum motu et ratione gubernans; ut Augustinus narrat, VII de Civ. Dei".

${ }^{25}$ (Trad. Alexandre Corrêa, 1980, modificada): "Quidam vero aestimabant totum mundum esse unum Deum, non propter corporalem substantiam, sed propter animam, quam Deum esse credebant, dicentes Deum nihil aliud esse quam animam motu et ratione mundum gubernantem; sicut et homo dicitur sapiens propter animam, non propter corpus. Unde putabant toti mundo, et omnibus partibus eius, esse cultum divinitatis exhibendum, caelo, aeri, aquae, et omnibus huiusmodi. Et ad haec referebant nomina et imagines suorum deorum, sicut Varro dicebat, et narrat Augustinus, VII de Civ. Dei”.
} 
o culto interior, a nomeação reverencial dos deuses, seja o culto exterior, a instituição dos artefatos que representam as partes do cosmo. Por conseguinte, conforme Tomás, Varrão confere justificativa filosófica para a idolatria: estabelece que deus é a anima mundi, a força incorpórea que locomove e governa o cosmo.

\section{Tomás de Aquino, crítico de Varrão}

À luz da filosofia, Tomás refuta a cosmologia de Varrão e o culto à anima mundi. A refutação, ademais, encontra-se virtualmente contemplada na crítica que Tomás estabelece à posição dos "gentios" (gentiles), nomeadamente quanto à tese segundo a qual Deus é forma cósmica. Nesse contexto, após argumentar que Deus não é forma cósmica, Tomás afirma que existe:

[...] o erro dos gentios que afirmavam que Deus é a alma do céu e até a alma do cosmo inteiro. Por causa desse erro, defendiam também a idolatria, ao afirmarem que o cosmo inteiro é Deus, não devido ao corpo, mas devido à alma; como também um homem é designado de sábio não por causa do seu corpo, mas, de sua alma. Por isso, afirmavam que o culto divino devia ser prestado ao cosmo e suas partes. (SCG I, 27, $8 \S) .{ }^{26}$

O termo "gentiles" é empregado por Tomás para compor o título de uma de suas principais obras, a saber, a Summa contra gentiles, escrita entre 1259-1264. Em sentido geral, o termo "gentiles" significa "não cristão". ${ }^{27}$ Nesse sentido, Tomás visa refutar o "erro" dos "não cristãos", seja no domínio da filosofia, ao refutar a proposição "Deus é a anima mundi", seja no domínio da religião natural, ao refutar a idolatria, esta que também é uma consequência, é importante lembrar, de concepções filosóficas.

Com o propósito de refutar a teoria da anima mundi, Tomás discorre sobre o assunto na SCG I, 27 e na SCG III, 120. Dentre as teses defendidas pelo autor, três podem ser tomadas como diretivas, uma cosmológica e duas metafísicas. São elas: (i) o cosmo necessita de um primeiro motor absolutamente imóvel (SCG I, 27, 5§); (ii) na criatura há uma distinção ontológica entre forma e ser (SCG I, 27, 2§); (iii) Deus é transcendente (SCG III, 120, 5§).

A tese cosmológica é estabelecida por Tomás nos seguintes termos:

\footnotetext{
26 " [...] gentilium error [...] qui dicebant Deum esse animam caeli, vel etiam animam totius mundi. Et ex hoc errorem idolatriae defendebant, dicentes totum mundum esse Deum, non ratione corporis, sed ratione animae, sicut homo dicitur sapiens non ratione corporis sed animae: quo supposito, sequi opinabantur quod mundo et partibus eius non indebite divinus cultus exhibeatur".

${ }^{27}$ Para o sentido geral de "gentiles" ver: ADLER, 1938.
} 


\begin{abstract}
O mesmo pode ser demonstrado a partir da eternidade do movimento, do seguinte modo. Se Deus é a forma de algum móvel, uma vez que ele é o primeiro motor, o composto será automovente. Porém, o automovente pode ser movido ou não movido. Portanto, tanto um como o outro encontra-se nele. Todavia, aquilo que é assim não possui em si mesmo independência de movimento. É necessário admitir, portanto, que acima do próprio automovente exista outro primeiro motor que confere a perpetuidade do movimento. Assim sendo, Deus, que é o primeiro motor, não é a forma do corpo automovente. (SCG I, 27, 5§). ${ }^{28}$
\end{abstract}

O movimento, isto é, a locomoção, pressupõe a coisa que o realiza, a saber: o móvel (mobilis). O móvel, por sua vez, numa perspectiva cosmológica da locomoção em geral, referese a uma outra parte constitutiva do cosmo, em locomoção natural, ou ao conjunto dos móveis em perpétua locomoção natural (céus e elementos), ou seja, o próprio cosmo. Numa ou noutra alternativa, o móvel é dito automovente, sendo composto de motor, o ato, e movido, a potência.

Tomás entende que o automovente não é absolutamente independente da locomoção: mesmo que ele não esteja hic et nunc em locomoção, estando, por conseguinte, em repouso, pode iniciar a locomoção. Essa possiblidade, intrínseca na natureza do automovente e, mais precisamente, em sua forma, torna o automovente dependente de outrem, um motor absolutamente imóvel, ou seja, cuja possiblidade de locomoção ou repouso inexiste, razão pela qual tal motor não pode ser entendido como a forma do automovente. Nesse sentido, sendo o automovente uma parte constitutiva do cosmo ou o próprio cosmo e, estando hic et nunc em locomoção perpétua e natural, ele necessita de um primeiro motor absolutamente imóvel que, para Tomás, é Deus.

Embora Tomás não empregue o termo "separado" (separatus) ou "distinto" (distinctio) quando articula as noções de primeiro motor e automovente na SCG I, 27, 5§, é razoável entender que a existência do primeiro motor está além da forma do automovente, sendo ele separado ou distinto dela. Se se entende que o automovente é o cosmo, então o primeiro motor não é a forma cósmica. Além disso, se o automovente encontra-se hic et nunc em perpétua locomoção natural, isso se deve também à causalidade eficiente do primeiro motor que, nesse caso, não apenas é causa essendi, o creator, mas também causa de locomoção, ou seja, a causa eficiente que determina que o automovente abandone o repouso, este que possui os requisitos para se manter em perene locomoção natural.

\footnotetext{
${ }^{28}$ (SCG I, 27, 5§): "Hoc idem potest ostendi ex aeternitate motus, sic. Si Deus est forma alicuius mobilis, cum ipse sit primum movens, compositum erit movens seipsum. Sed movens seipsum potest moveri et non moveri. Utrumque igitur in ipso est. Quod autem est huiusmodi, non habet motus indeficientiam ex seipso. Oportet igitur supra movens seipsum ponere aliud primum movens, quod largiatur ei perpetuitatem motus. Et sic Deus, qui est primum movens, non est forma corporis moventis seipsum”.
} 
Pelo que se nota, a noção de forma é basilar para a compreensão da relação entre o primeiro motor e o automovente, isto é, entre Deus e o cosmo. Além do argumento cosmológico descrito, Tomás ainda emprega a noção de forma no argumento metafísico que sustenta a distinção ontológica entre a forma e o ser em todos os entes, com exceção de Deus. Tal argumento é sintetizado pelo doutor angélico mediante a seguinte sentença: "A forma do corpo não é o ser mesmo, mas o princípio de ser". ${ }^{29}$ É importante observar, por um lado, que a distinção entre a forma e o ser, no argumento presente na $S C G \mathrm{I}, 27,2 \S$, é direcionada à noção de corpo e, por outro lado, que essa distinção também se aplica aos entes incorpóreos (inteligências/anjos), como o próprio autor estabelece na SCG II, cc. 50-54.

A restrição da distinção entre a forma e o ser na SCG I, 27, $2 \S$ visa justamente criticar a identificação entre Deus e anima mundi, uma vez que a teoria dos gentiles sustenta que deus enquanto forma é a alma e o cosmo, por seu turno, o corpo. São, ademais, duas as proposições que Tomás necessita refutar antes da crítica à identificação mencionada: "Deus é forma corpórea" e "Deus é alma corpórea". Para tanto, o autor sustenta que a forma (corpórea) é o princípio do ser (principium essendi), deve, por conseguinte, ser distinta do ser em si (ipsum esse), isto é, do ser que não possui princípio.

A noção metafísica de princípio, no argumento da distinção entre a forma e o ser na SCG I, 27, 2§, denota a mediação entre o ser e o corpo. O corpo só possui ser porque a forma transmite ser ao corpo, ou seja, ela medeia a relação entre o ser e o corpo. A forma é, portanto, o princípio do ser do corpo. Como a noção de corpo, para Tomás, sempre é dita para as coisas da natureza, ou seja, para as coisas constituídas de matéria e forma, na constituição do corpo o ser relaciona-se com a matéria a partir da forma. Nesse sentido, o corpo é constituído por três constituintes realmente distintos: o ser, a forma e a matéria. É por esse viés que pode ser entendido o final do argumento da $S C G$ I, 27, 2§: “[...] Deus é o ser em si. Logo, ele não é forma corpórea." ${ }^{30}$ Ora, se Deus não é forma corpórea, então ele não pode ser a forma cósmica: para os gentiles, conforme já indicado, o cosmo é o corpo do todo.

A conclusão da SCG I, 27, 2§ também auxilia a compreender a tese defendida por Tomás na SCG III, 120, 5§, qual seja: Deus é transcendente (exaltatus), pois se Deus não é a forma cósmica, mas existe, então ele está além do cosmo. Ademais, não deixa de ser intrigante constatar que Tomás se serve da tese da transcendência divina para justificar filosoficamente

\footnotetext{
29 "Forma corporis non est ipsum esse, sed essendi principium".
}

30 “[...] Deus est ipsum esse. Non ergo est Deus forma corporis". 
que apenas Deus é digno de culto, vinculando, por conseguinte, filosofia e religião. O argumento encontra-se resumido na seguinte passagem:

\begin{abstract}
Ora, não podemos afirmar uma opinião sobre Deus no tocante à sua unidade e à sua transcendência absoluta senão quando apresentamos a Deus algo separadamente, e isto designamos de culto divino. (SCG III, 120, $5 \S) .{ }^{31}$
\end{abstract}

O homem deve atribuir algo separado a Deus, o culto divino, segundo Tomás, porque Deus, ele mesmo, é separado, ou seja, está além do cosmo. A separação divina com relação ao cosmo pode ser compreendida a partir de uma afirmação encontrada na SCG I, 27, 2§, isto é, Deus é o ser em si, o que significa dizer que Deus existe e que sua existência não tem causa. Assim sendo, tem-se, por um lado, a evidência sobre a existências das coisas sensíveis e, por outro lado, a admissão filosófica da existência de algo que existe além das coisas sensíveis, Deus, sendo ele a causa que confere a existência às coisas sensíveis e ao próprio cosmo. Nesse sentido, se Deus é transcendente e causa essendi, não é a forma cósmica, logo, é inconsistente sustentar que ele seja a anima mundi e, consequentemente, a prática da idolatria, como pretendia a cosmologia de Varrão.

\title{
REFERÊNCIAS BIBLIOGRÁFICAS
}

ADLER, M. J. Saint Thomas and the Gentiles. Milwaukee: Marquette University Press, 1938. AGOSTINHO. De Civitate Dei. In: Sancti Aurelii Augustini Opera, pars XIV, Corpus Christianorum Series Latina 47-48. Turnhout: Brepols, 1960. 1996-2000.

A cidade de Deus. Trad. João Dias Pereira. Lisboa: Fundação Calouste Gulbenkian,

ALGRA, K. Stoic philosophical theology and graeco-Roman religion. In: SALLES, R. (ed.). God and Cosmos in Stoicism. Oxford: Oxford University Press, 2009. p. 224-252.

BELliOTTI, R. A. Roman Philosophy and the Good Life. Lanham; Boulder; New York; Toronto; Plymouth: Rowman \& Littlefield Publishers, 2009.

BOURKE, V. J. St. Augustine and the Cosmic Soul. Giornale di Metafisica, Gênova, v. 9, 1954, p. 431-440.

DUHOT, J-J. La conception stoïcienne de la causalité. Paris: Vrin, 1989.

FURLEY, D. Cosmic Problems. Essays on Greek and Roman Philosophy of Nature. Cambridge: Cambridge University Press, 1989.

31 “Opinio autem de hoc quod Deus sit unus, supra omnia exaltatus, per sensibilia firmari non potest in nobis nisi per hoc quod ei aliquid separatim exhibemus, quod dicimus cultum divinum". 
GIL, C. The Structured Self in Hellenistic and Roman Thought. Oxford-New York: Oxford University Press, 2006.

JAEGER, Werner. Aristoteles: bases para la historia de su desarrollo intellectual. Pánuco, Mexico: Fundo de Cultura Economica, 1946.

La Teologia de los Primeros Filosofos Griegos. Trad. de José Gaos. México-Buenos Aires: Fondo de Cultura Económica, 1952.

. Early Christianity and Greek Paideia. Cambridge (Mass.): Harvard University Press; London: Oxford University Press, 1961.

MEIJER, P. A. Stoic Theology. Proofs for the Existence of the Cosmic God and of the Traditional Gods. Including a Commentary of Cleanthes' Hymn on Zeus. Delft: Uitgeverij Eburon, 2007.

MOREAU, J. L'âme du monde de Platon aux Stö̈ciens. Paris: Les Belles Lettres, 1939.

MULLER, R. Les Stoïciens. La liberté et l'ordre du monde. Paris: J. Vrin, 2006.

SEDLEY, D. Stoic metaphysics at Rome. In: SALLES, R. (ed.). Metaphysics, Soul, and Ethics in Ancient Thought: Themes From the Work of Richard Sorabji. Oxford-New York: Clarendon Press, 2005. p. 117-142.

PEPIN, Jean. La "théologie tripartite" de Varron. Essai de reconstitution et recherche des sources. Revue d' Etudes Augustiniennes Et Patristiques, Paris, v. 2, 1956, p. 265-294.

THOMAE DE AQUINO. In octo libros physicorum Aristotelis expositio. Commissio Leonina, t. II, Roma: Typographia Polyglotta, 1884.

. In libros Aristotelis De caelo et mundo. Commissio Leonina, t. III, Roma: Typographia

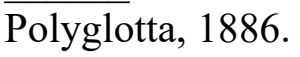
$\overline{1888-1906 .}$

Summae Theologiae. Commissio Leonina, t. IV-XII. Roma: Typographia Polyglotta,

Summa contra gentiles. Commissio Leonina, t. XIII-XV. Roma: Typis Riccardi Garroni, 1918-1930.

Lethielleux, 1925.

Quaestiones Disputatae de Potentia Dei. Ed. P. Mandonnet, vol. II, Paris: P. Scriptum Super Libros Sententiarum Magistri Petri Lombardi. Ed. P. Mandonnet Vol. 1-2. Paris: P. Lethielleux, 1929.

. In duodecum libros Metaphysicorum Aristoteli expositio, ed. M.-R. Cathala, rev. R.M. Spiazzi. Turin: Marietti, 1950.

Marietti, 1953.

Catena aurea in quatuor Evangelia, t. 2: Expositio in Ioannem. Taurini-Roma: . Super Evangelium S. Ioannis lectura. Taurini-Roma: Marietti, 1972.

1982.

Quaestiones disputatae de malo. Commissio Leonina, t. XXIII. Roma - Paris: J. Vrin, . Sentencia libri De anima. Commissio Leonina, t. XLV-1. Roma - Paris: J. Vrin, 1984. 

1992

. Super Boetium De Trinitate. Commissio Leonina, t. L. Roma - Paris: Éditions du Cerf, Suma de Teologia (11 vols.). Trad. Alexandre Correia. Porto Alegre: Livraria Sulina Editora, 1980.

Suma contra os gentios (2 vols.). Trad. Odilão Moura. Porto Alegre: Livraria Sulina Editora, 1993.

TORRELL, Jean-Pierre. Iniciação à Santo Tomás de Aquino: sua pessoa e obra. São Paulo: Loyola, 1999. 